\title{
Visualizing and gamifying consumption data for resource saving: challenges, lessons learnt and a research agenda for the future
}

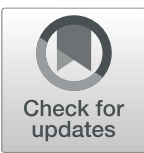

\author{
Piero Fraternali ${ }^{1}$, Francesca Cellina ${ }^{2 *}$, Sergio Luis Herrera Gonzales ${ }^{1}$, Mark Melenhorst ${ }^{3}$, Jasminko \\ Novak $^{3,5}$, Chiara Pasini ${ }^{1}$, Cristina Rottondi ${ }^{4,6}$ and Andrea Emilio Rizzoli ${ }^{4}$
}

From The 8th DACH+ Conference on Energy Informatics

Salzburg, Austria. 26-27 September, 2019

\author{
${ }^{*}$ Correspondence: \\ francesca.cellina@supsi.ch \\ ${ }^{2}$ Institute for Applied Sustainability \\ to the Built Environment (ISAAC), \\ University of Applied Science and \\ Arts of Southern Switzerland \\ (SUPSI), Campus Trevano, 6952 \\ Canobbio, Switzerland \\ Full list of author information is \\ available at the end of the article
}

\begin{abstract}
In this paper we present insights drawn from recent research projects aimed at developing visualization and gamification tools to stimulate individual behaviour change and promote energy and water saving. We address both the design of resource-saving programmes and the methodologies to assess their effectiveness. We conclude by presenting a vision for the future and discussing open issues that could lead future research directions in the field of behavioural change approaches to resource sustainability.
\end{abstract}

Keywords: Demand-side-management, Behaviour change, Feedback, Gamification

\section{Introduction}

Individual consumption of natural resources, such as gas, electricity and water, has a significant environmental impact. Following progress in information and communication technology (ICT) and large-scale smart metering roll-out programmes, several initiatives in research and industry have recently pioneered demand-side management through ICT-based behavioural change approaches, to help people increase awareness on their consumption patterns and motivate them to reduce their level of consumption and/or shift it to off-peak periods (Geelen et al. 2013; Goulden et al. 2014; Verbong et al. 2013). For instance, a recent review on ICT-based electricity saving initiatives in households showed they have a potential to reduce household final electricity consumption by $0-5 \%$ (Bastida et al. 2019). Usually these initiatives provide an (eco-)feedback (Froehlich et al. 2010) through the intuitive visualization of consumption data, collected by smart metering infrastructures, and deploy behavioural change stimuli, aimed at inducing resource saving by consumers. For this purpose, gamification principles, mechanics and elements (Weiser et al. 2015) are frequently exploited in attractive interfaces that favour the consumers' engagement, provide them with guidance for improving their resource-saving behaviour and reward their progress towards change.

(c) The Author(s). 2019 Open Access This article is distributed under the terms of the Creative Commons Attribution 4.0 International License (http://creativecommons.org/licenses/by/4.0/), which permits unrestricted use, distribution, and reproduction in any medium, provided you give appropriate credit to the original author(s) and the source, provide a link to the Creative Commons license, and indicate if changes were made. 
This paper reports on the experience of several demand-side management projects which tested the impact of consumption visualization, contextual recommendations, gamification and games in managing energy demand of consumers in residential, business, and public buildings.

After providing a brief overview of a number of demand-side management projects which have recently been developed ("Recent ICT-based demand-side management interventions" section), we highlight the main lessons learned and the challenges met in designing effective behavioural change programs ("Technical and design challenges" section). Finally, we provide our vision for the future research agenda in this field ("Conclusions: lessons learnt and future research agenda" section).

\section{Recent ICT-based demand-side management interventions}

Several ICT-based interventions targeting behavioural change for resource savings have been recently run throughout Europe, exploiting tools developed on purpose. For instance, Table 1 reports a non-exhaustive list of projects which focused on the reduction of energy (mostly, electricity and gas) and water consumptions.

Most of them target public buildings (CHARGED, ENTROPY, GAIA, GreenSoul, ORBEET, TRIBE), e.g. public offices, schools, museums, municipality buildings, universities, and research institutes, whereas others address residential buildings and their inhabitants (enCOMPASS, EnerGAware, Peakapp, SmartH2O, Social Power). They all leverage ICT-based infrastructures for the collection and processing of resource consumption data gathered from smart meters as well as measurement data from heterogeneous sensors, such as presence, movement, luminance, temperature, humidity sensors, or smart plugs. Frequently through ad-hoc middleware solutions, such data is then elaborated by platforms integrating different modules and services. Typically, modeling modules are adopted to reconstruct virtual scenarios replicating the characteristics of the monitored buildings, to run what-if experiments and assess the impact of the application of various resource saving interventions. Additionally, meter and sensor data are processed to extract knowledge about the activity patterns of the users, which is then used to provide adaptive and contextualized recommendations about possible resource saving actions (enCOMPASS, Charged, GreenSoul, SmartH2O). Such recommendations are typically incorporated in gamified mechanics aimed at raising users' awareness on the importance of reducing consumption and its effects/implications. Different game designs have

Table 1 A selection of ICT-based interventions promoting behavioural change for resource saving

\begin{tabular}{llll}
\hline Project & Website & Target Resource & Target group \\
\hline CHARGED & www.charged-project.eu & electricity and heating & Offices \\
enerGAware & www.energaware.eu & electricity and heating & Households \\
ENTROPY & www.entropy-project.eu & electricity and heating & Offices \\
GAIA & www.gaia-project.eu & electricity and heating & Schools \\
enCOMPASS & www.encompass-project.eu & electricity & Households, schools, offices \\
GreenSoul & www.greensoul-h2020.eu & electricity & Offices \\
ORBEET & www.orbeet.eu & electricity and heating & Offices \\
PeakApp & www.peakapp.eu & electricity & Households \\
SmartH2O & www.Smarth20-fp7.eu & water & Households \\
Social Power & www.socialpower.ch & Electricity & Households \\
TRIBE & www.tribe-h2020.eu & electricity and heating & Households, schools, offices \\
\hline
\end{tabular}


been tested, ranging from trivia and quiz-like games (SmartH2O, enCOMPASS, GAIA, PeakApp) to strategy-based games (EnerGAware, ENTROPY, TRIBE), and often socialrelated features such as leaderboards (EnerGAware, SmartH2O, enCOMPASS, GAIA) or teams (Social Power) are exploited as well. The underlying design principles have their roots in behavioural sciences and aim at engaging the user in an educational path through the steps of behaviour change (Prochaska and Velicer 1997), by rewarding her resource saving attitudes. Economical incentives, deriving for instance by the application of dynamic time-of-use tariffs have also been exploited to induce behavioural changes in energy and water consumption (PeakApp, SmartH2O).

\section{Technical and design challenges}

Based on the experience with the above-mentioned projects, gained while either directly running and managing them or interacting with them in the framework of cluster activities for EU Horizon 2020 funded projects on the same research topics, we identified the ten most frequent technical and design challenges, which might affect the effectiveness of demand-side management interventions targeting resource saving: here we introduce them and provide suggestions on how to overcome them.

\section{Acquiring data}

Despite the increasing diffusion of smart digital meters (Fang et al. 2012), data acquisition is still a challenge. Ensuring scalability in the deployment of Automated Metering Infrastructures (AMIs) (Yan et al. 2013), which are expected to span geographically wide regions including millions of inhabitants, involves many practical issues: network coverage and signal transmission quality might be impaired by adverse environmental conditions (especially in rural areas) or achievable only at non-competitive installation costs (Depuru et al. 2011). Moreover, in the case of water resources, most smart meters run on batteries, which limits the data transmission frequency, and are connected to the data infrastructure of the utility company with ad-hoc proprietary networks. Even when an AMI is available, the reception of data is still highly problematic. Errors and delays in data transmission are more the norm than the exception: therefore, the correctness of the metered data must be guaranteed by means of computationally expensive validation procedures, and consumption analytics at individual and aggregated level must be computed to support real-time services (Pitì et al. 2017). Errors or delays in data transmission are extremely troublesome when gamified approaches are exploited: if the system is designed to reward the users' progress on a periodic basis (say, every day), one cannot alter the rules of the games because of missing or corrupted data. Further challenges affect data collection when an AMI is not available and users must voluntarily providing meter readings manually. Since manual data entry has to be systematically repeated over time, it issues challenges about how to guarantee user engagement over time and how to set unbiased baselines.

Manual data collection is a well known and problematic aspect of system design, as demonstrated by the few efforts in this direction (e.g. the Munx system in Switzerland (Munx)). In fact, first of all users are requested an effort, for which they need to be somehow rewarded. As a possible rewarding strategy prizes might be raffled out among all those who have regularly introduced their data, so that their baseline can be computed. 
Alternatively, building of the baseline might be included in the gamified activities, by attributing virtual rewards to the users who manually enter enough consumption data.

\section{Setting baselines}

Baseline data may be used both directly within the demand-side-management tool, to show user progress with respect to her initial average behaviour, and to assess effectiveness of an intervention, through a before/after comparison of data collected in similar conditions. Collecting reliable baseline data requires to span long period of times, enough to account for a wide variability in the independent variables that might affect consumption patterns, such as the weather conditions, the length of the day, the day of the week, or the month of the year. However, if hypotheses can be made regarding variables such as the season of the year, ensuring similar conditions for variables such as "household composition" or "household equipment of electric appliances" is much more challenging, since these variables cannot be controlled, when the demand-side-management interventions are lead in real-life settings.

Baseline setting is further challenging when AMIs are not available and users are requested to manually enter their meter readings. The data entry activity might in fact introduce two types of biases impairing reliability of the gathered baseline. First, an Hawthorne effect might take place - which happens when users alter their behaviour towards a more socially desirable one (lower energy consumption than usual), due to awareness of being observed (Adair 1984; Adams et al. 2005; Nichols and Maner 2008; Tiefenbeck 2016). Second, regular data entry might act as an unintended feedback on their consumption patterns, and thus start to actively persuade them to change their behaviour, thus impairing reliability of baseline values.

\section{Ensuring engagement}

The most challenging task of a socio-technical system involving people on a voluntary basis is engagement. First, this requires to address a recruitment problem and to get people use the demand-side-management tool; then, it requires to address how to maintain their engagement over time.

Recruitment of the participants to demand-side management interventions is usually performed by means of public advertising and communication activities, through flyering, traditional mass media and social networks (self-selection recruitment strategies). In such voluntary opt-in frameworks, it is likely that individuals with higher environmental awareness and pro-environmental attitude are stimulated to join the tool, while "mainstream" citizens simply ignore the invitations (Hartman 1988; Tiefenbeck et al. 2019). To reduce this self-selection bias, "opt-out" frameworks should be preferred, for example by involving municipal authorities or utility companies to formally notify possible users they have been selected to join an innovative demand-side-management programme. This would imply that all target groups are by default enrolled in a programme, from whom they are requested to formally withdraw, if they are not interested in participating (Pichert and Katsikopoulos 2008; Frederiks et al. 2015). Such an approach would not definitively solve the problem, however, since no obligations to join behaviour change programmes can be put into force. A further way to raise the interest of "mainstream citizens", that however still needs to be supported by sound experimenting on the field, would be to offer real-life rewards. Since use of extrinsic motivational factors is controversial 
(Deci 1971), prizes could at first be exploited to engage people with low intrinsic motivation for change, and later on could gradually be replaced by less tangible, intrinsic motivational factors, as long as people get engaged by the programme (Ryan and Deci 2000).

Once the challenge of engaging people has been addressed, the problem remains about how to maintain engagement over time. Attempts to promote individual behaviour change by means of ICT-based interventions might in fact be affected by high drop-out rates, such as for instance in the Social Power intervention, within whom $40 \%$ of participating households dropped out of a three month app-based gamified intervention (Wemyss et al. 2019). A strategy to maintain users engaged for longer periods might be to leverage social relationships, building on already existing, real-life relations within a community and blending the behavioural change messages and programmes seamlessly in their activity. For example, within citizen science processes, very large and active trekking and mountaineering groups are engaged in data collection for climate change impact monitoring. Similarly, targeting members of a community such as a school, a company, or even a sport club (e.g. work colleagues, class mates and their families, etc.) could favour a larger diffusion of the impact of behaviour change initiatives: exploiting the network of formal relations of individuals within their community is expected to help creating a stronger commitment for participants, to remain active until they manage to adopt new consumption patterns (Frick et al. 2017). Another strategy might be to opt for opening-up the design of the intervention main contents and activities to the citizens themselves, in a living lab-style co-creation collective effort (Pallot et al. 2010). The underlying hypothesis being that, if they own the intervention, individuals will be stimulated to remain active for a longer period of time and promote it among their circle of family and friends. Evidence of effectiveness of both the above mentioned strategies (anchoring to real-life relations and favouring co-creation) is however still to be collected. Therefore, how to maintain user engagement over time remains an open challenge.

\section{Designing for different motivations}

Designing an effective behavioural change system requires that the adopted strategies for stimulating awareness and engagement (e.g. through visualization of consumption and gamification) address a wide group of potential users, with different motivations and affinities. Catering to a heterogeneous group of users poses a range of design challenges. On one hand, different users have different environmental goals and values (Lindenberg and Steg 2007), as well as different needs with regard to energy consumption feedback, among others because users differ in terms of their behavioural change progress. Second, the structural characteristics of energy consumption behaviour as abstract, non-sensory, comprised of multiple behaviours, and of low personal relevance to most individuals (Karlin 2015) impose challenges on the designers of energy consumption visualizations, among which representation of energy data in meaningful units, as well as the temporal grouping of data (e.g real-time, by day, week or month). For example, previous research has demonstrated that the abstract units commonly used for energy consumption (e.g. kWh) are difficult to understand for household users (Karjalainen 2011). To address this, a metaphor-based visualization approach (e.g. eco-visualizations that map energy consumption to objects from nature ) can help users cope with the cognitive load of interpreting complex numerical and abstract information. 
One strategy to account for such differences is to provide multiple layers of detail and representations of the consumption feedback, to allow users with different data affinity and intrinsic or extrinsic motivations to switch between views that best fit their needs. Also, alternative metaphors that map the consumption from $\mathrm{kWh}$ to different types of visualizations can be used reduce the cognitive load inflicted on the user, and to facilitate comprehension. Determining which types of metaphors to use can be based on key motivational drivers, such as those provided by the goal-framing theory, that distinguishes between egoistic values (e.g. money), altruistic values (e.g. environmental values) and hedonic values (e.g. gratification, fun).

Similarly, while some users are motivated more by intrinsic drivers, others will be more responsive to extrinsic incentives (e.g. the prospect of winning prizes or rewards). Applying competitive or collaborative mechanisms as a stimulus for user engagement will also provide different results depending on how well different users respond to the one or the other. While introducing competition to motivate engagement is widely spread in gamification approaches, some contributions from related domains (e.g. stimulating water saving) recommend making competition optional and stressing collaboration instead (Froehlich et al. 2012). Different user types may also place different importance on the pragmatic affordances of a system (i.e., its practical usefulness and functionalities), whereas others my place a higher value on hedonic affordances (e.g. the systems attractiveness, its visual design, joy of use etc.) (Venkatesh et al. 2012). Accordingly, a welldesigned behavioural change system should combine a spectrum of incentives and design elements that address multiple motivational drivers and preferences of different types of users.

\section{Modeling users to fine tune gamification}

A cornerstone of gamification is observing users' actions, computing achievements (e.g. verifying if a saving goal was met ) and acknowledging them with a reward (e.g. a virtual one, such as a badge or a status promotion, or a real one, such as a prize or a discount). Achievements are quantified with points, which serve the purpose of reducing heterogeneous actions to a common metrics, enabling comparison, competition and rewarding. A critical issue in the design of a gamified mechanics is the assignment of points to actions; in presence of an ample spectrum of actions, that can be performed by users with different capabilities and living in different contexts, deciding the right amount of points for each action deeply influences the dynamics of the whole system and can emphasize alternative aspects of the user's response, possibly determining the ultimate impact on behaviour (Scheider et al. 2015). To this aim, agent-based modeling (Zheng et al. 2014) can help understand the dynamics of the socio-technical system and predict its behaviour, under different point assignment schemes.

Several research efforts have been devoted to Non Intrusive Appliance Load Monitoring (NIALM), which aims at decomposing the aggregate household energy/water consumption data collected from a single measurement point (e.g. the smart meter installed at the customer's premises) into device-level consumption data (for a thorough survey the reader is referred to Zoha et al. (2012); Cominola et al. (2015)). Such disaggregated information can be exploited to refine the rewarding mechanisms, by targeting energy saving actions at the individual appliance level. Disaggregation can be facilitated by the installation of sub-metering devices such as smart plugs or sensors on-device, which 
track the individual consumption patterns of the main electrical/water appliances, or of light/presence/temperature sensors, which enable the analysis of correlation between energy/water consumption events (Zoha et al. 2012). Though most of state-of-the-art methods are capable of accurately estimating the average fraction of energy/water consumed by each appliance, the reconstruction of individual consumption patterns is much more problematic, thus limiting the potential feedback that could ideally be inferred by such a knowledge. This is especially true if the granularity of the metered data is coarse (e.g. one sample every 15 or $60 \mathrm{~min}$, which represent the most commonly adopted standards in current smart metering systems). Indeed, most of the approaches investigated by the scientific community assume that consumption data at minute (or even sub-minute) granularity are available. Moreover, stimulating behaviour change effectively requires visualization of NIALM outputs that is easily understandable at a glance and seamlessly embedded into user's context, offering details and comparisons based on the current activity situation, and relating it to possible energy saving actions. Closing this loop effectively in a user-friendly way is still an open challenge.

\section{Providing guidance and education}

behavioural change schemes based on gamification assume that an engaged user is triggered towards a more sustainable pattern of consumption. However, such a transition may require knowledge not fully possessed by the user about the best way to improve consumption. Therefore, the need arises to blend educational content (e.g. how-to videos, resource saving tips and recommendations) within the consumption visualization and gamification approach. On one side, educational materials can be juxtaposed to other behavioural change stimuli, in the hope that the activated user, motivated by gamification incentives, takes the time to explore them. A more integrated approach injects educational hints into the very core of the gamification elements. For example, SmartH2O (Micheel et al. 2015) exploits the synergy between a card-based board game named "DROP! The question", a gamified online portal, and a mobile application, to trigger behavioural changes in water conservation attitudes of users.

Another example of close integration between learning and gamification elements is provided by the Social Power app, which targets reduction in household electricity consumption (Wemyss et al. 2018). Every week, the app launches thematically focused tips and challenges, as step-by-step guides to support households in changing their patterns of use of appliances. Each time a challenge is completed, users are rewarded with points, so that such a positive reinforcement increases their intention to adopt the behaviour in the feature and make it a new habit (Kurz et al. 2015). Such an action-oriented, gamified learning approach provides a model of learning that occurs simply by doing sustainable activities within real-world.

\section{Respecting privacy}

The drawback of collecting fine grained consumption data and of applying NIALM techniques is user exposure to potential privacy breaches: though the information obtained via disaggregation approaches can lead to useful insights on individual energy usage habits, it can also be exploited by unauthorized entities to learn potentially sensitive details such as household occupation periods, number of occupants, cooking, or sleeping patterns (Yan et al. 2012). This would potentially lead to harmful consequences, e.g. burglars attempting 
robberies when houses are sensed as unoccupied or companies designing targeted marketing campaigns based on individual usage statistics. To avoid such drawbacks, several technical solutions have been proposed, ranging from privacy-preserving cryptographic protocols for metering data collection to mechanisms based on noise injection and techniques which intelligently exploit the charge/discharge cycles of a locally installed battery to alter the individual consumption patterns (Yan et al. 2012). Among such solutions, only the latter two ensure compatibility with the application of NIALM algorithms, however at the price of reducing their effectiveness due to the induced distortions in the metering data,if no proper aggregation techniques are exploited (Rottondi et al. 2013; Chen et al. 2018).

\section{Assessing the effects}

If a statistically sound analysis of the effects of the demand-side-management programme is envisioned, whenever possible an experimental design (randomized controlled trial) has to be adopted, or at least a quasi-experimental one (Vine et al. 2014; Frederiks et al. 2016). This implies that both a treatment and a control group must be activated, and a comparison of the after/before resource-consumption behaviour of both the treatment and the control group has to be performed. Recruitment of the control group must be carefully planned, to avoid any unintentional influence on the behaviour of the group members, by the above-mentioned Hawthorne or "social approval" effects. If the demandside-management programme addresses a centralized-distributed resource, the easiest way to access control group consumption data would be to unobtrusively access historical consumption data of a comparable group of target users, that were already collected and stored by the utility company. This would not allow to perfom a randomized controlled trial, since no random assignment to the control or the intervention group would be possible, thus leading to perform a quasi-experiment; however, would avoid introducing any biases in the control group consumption data. To guarantee privacy regulations are respect, users in the control group would however need to explicitly provide the utility company with informed consent to access their sensible consumption data.

\section{Ensuring post-intervention impact}

Let's suppose a demand-side management programme managed to produce the expected outcome and prompted adoption of less resource-intensive consumption patterns. However, the challenge remains for the intervention to create new enduring habits, and not just a short-term effect (Allcott and Rogers 2014). Only a few studies monitored the effects of resource-saving interventions long after their conclusion, and there is not enough evidence to generalize their results and assess long-term effectiveness of different types of interventions. For instance, (Hargreaves et al. 2013) and (Schleich et al. 2017) came to opposite conclusions, regarding long-term effects of similar electricity-saving interventions, consisting in endowing households with in-home displays of electricity consumption and providing them with a feedback. The former (Hargreaves et al. 2013) reports that the statistically significant effects produced by the intervention in the short-term tended to disappear in the long-term, namely one year after the intervention itself, since the information provided by the display was quite consistent, thus providing no new motivation and input to save electricity. Instead, for a similar 11-month long intervention with households, the latter (Schleich et al. 2017) reports statistically 
significant long-term savings. More recent research found that positive effects on longterm energy consumption could be produced, provided that normative feedback messages are continued over time (Anderson et al. 2017). Such results can be framed within the transtheoretical model of behaviour change (Prochaska and Velicer 1997), according to whom behaviour change occurs through progression by a series of stages: as long as individuals practice with the implementation of the new behaviour, they enter the maintenance stage, during which the need for external support progressively decreases, they are less tempted by relapse and are more confident that they can regularly put the new behaviour into practice. However, relapse is always possible, therefore specific actions need to be activated to avoid it, just like during the intervention itself. Empirical experience reported above teaches us that, though probably necessary, providing visualization of one's own resource consumption is generally not enough to maintain the positive shortterm impacts over time. Additional motivational elements, as also suggested by Prochaska and Velicer (1997); Ohnmacht et al. (2017); Wemyss et al. (2019), might be continuing push-notifications about resource-saving challenges or tips, or offering comparative feedback possibilities with similar households, thus embedding the feedback information in the real-life social context of the users, even better if also exploiting pre-existing channels (Breukers and Mourik 2013).

\section{Avoiding rebound effects}

Even when demand-side-management programmes maintain their long-term effectiveness, one cannot exclude that they indirectly produce increases in resource consumption, by the so-called "rebound effect" (Greening et al. 2000). Rebounds can in fact take place either directly, if lower billing costs lead individuals to increase consumption of the resource itself, or indirectly, if individuals realize they can invest the saved money in other resource-intensive products and services, such as a new tablet or an overseas holiday. Depending on the type and duration of the demand-side management programme, rebounds can already start occurring during the intervention or only appear once it has ended, especially for indirect rebounds and if households receive summary evaluations of their performances, for example through home energy reports (Allcott 2011). In the worst case, such induced increases in consumption might be so high, that they would over-compensate the savings induced by the demand-side-management programme, and the overall resource consumption would turn out to be larger at the end of the programme, than before its start (backfire effect).

Even though the amount of rebound effects affecting an intervention are still questioned (Gillingham et al. 2013), framing a resource-saving intervention within a wider environmental, climate and energy awareness and education programme might help limiting its rebound perverse effects.

\section{Conclusions: lessons learnt and future research agenda}

In this paper we have identified the ten most recurrent and critical challenges affecting ICT-based eco-feedback and gamification programmes targeting resource saving. Drawing from practical experience in a number of real-life interventions, we advanced recommendations to address them and identified topics requiring further investigation. Summarizing the lessons learnt from these experiences, and considering the 
remaining open challenges, we conclude by sketching an agenda for future research activities aimed at supporting individuals towards more sustainable resource consumption patterns.

Favour direct data exposure to the users to enhance privacy Most consumer engagement projects depend on utility companies to access consumption data and give such data back to the users, who in principle are the legitimate owners. Ways should be explored to empower the consumers to see their own data directly, without dependency on the utility companies, in a more "do-it-yourself" manner. By promoting the design of smart metering devices that comprise user interfaces or can display data directly on the consumers' devices (e.g. on their smartphones), consumer engagement apps would not need to depend on data exported outside the users' premises, thus reducing privacy risks.

Develop longitudinal studies over time Demand-side management programmes have a necessarily limited life-cycle (typically three years). Behavioural change processes, however, demand a sustained effort, to first collect meaningful and reliable baselines and then to observe impacts over time. Thus, long-term funding schemes should be created, to allow maintaining ICT demand-side management platforms and interventions over longer periods of time.

Combine production and consumption in behavioural change Many demandmanagement and engagement techniques leverage the ecologic attitude of consumers, who engage based on their willingness to contribute to environmental conservation. As renewable energy becomes more and more available to users, also at the level of selfand micro-generation, a new approach to consumer engagement should merge demandside and production-side management. Users could be rewarded not only for the way in which they reduce consumption, but also for their commitment to clean energy production, according to the "prosumer" concept (Parag and Sovacool 2016), or for rethinking their consumption practices in order to reduce the load on the grid. Such a joint approach to engagement could greatly increase the impact of behavioural change applications, because a broader spectrum of stimuli could be exploited. This would also expand the reach of such schemes, which are being experimented within a few national contexts (e.g. Germany or Switzerland), thus producing a greater impact at the global scale.

Develop multi-domain behavioural change and life motivators Behavioural change applications targeting individual consumption reductions could approach the consumption of multiple resources, e.g. electricity, gas and water, in a holistic manner. The ideal approach would be to design "better life motivators" for individuals, addressing all the aspects in which they can make a contribution (energy and water consumption, mobility, production, circular economy, waste, etc.). This would increase the global impact of the intervention, allowing the recommendation of actions that benefit more than one aspect and also favouring positive spillover effects (Truelove et al. 2014). Also, the effort of developing behavioural change apps and platforms would be better justified by the application to multiple domains. 
Promote an open European repository of behaviour change resources Behavioural change applications require the collection of content to address the consumers: questionnaires, educational videos, tips, stories, trivia, etc. Projects tend to develop such valuable resources independently. A coordinated action could be promoted in order to build a unique open repository of European resources, easily translatable in all the languages of the Union, so to reduce the cost and time to market of behavioural change solutions. This initiative would build a body of knowledge at the European level and make project efforts more uniform and thus comparable.

\section{About this supplement}

This article has been published as part of Energy Informatics Volume 2 Supplement 1, 2019: Proceedings of the 8th DACH+ Conference on Energy Informatics. The full contents of the supplement are available online atăhttps:// energyinformatics.springeropen.com/articles/supplements/volume-2-supplement-1.

\section{Authors' contributions}

Conceptualization: PF, JN, FC, CR; Writing - Original Draft Preparation: PF, JN, FC, CR; Writing - Review and Editing: SH, MM, $\mathrm{CP}, \mathrm{AER}$; Supervision: PF, JN, AER. All authors read and approved the final manuscript.

\section{Funding}

This paper was partially supported by the Horizon 2020 programme of the European Commission, within the enCOMPASS research project (Grant Agreement number 723059, H2020-EE-2016-2017/H2020-EE-2016-RIA-IA).

\section{Availability of data and materials}

No additional data and materials are associated to this article.

\section{Competing interests}

The authors declare that they have no competing interests.

\section{Author details}

${ }^{1}$ Dipartimento di Elettronica, Informazione e Bioingegneria, Politecnico di Milano, Piazza Leonardo da Vinci, 32, 20133 Milano, Italy. ${ }^{2}$ Institute for Applied Sustainability to the Built Environment (ISAAC), University of Applied Science and Arts of Southern Switzerland (SUPSI), Campus Trevano, 6952 Canobbio, Switzerland. ${ }^{3}$ European Institute for Participatory Media, Pariser Platz 6, 10117 Berlin, Germany. ${ }^{4}$ IDSIA USI-SUPSI, Galleria 2, 6928 Manno, Switzerland. ${ }^{5}$ University of Applied Sciences Stralsund, Zur Schwedenschanze 15, 18435 Stralsund, Germany. ${ }^{6}$ Politecnico di Torino, Corso Duca degli Abruzzi 24, 10129 Torino, Italy.

\section{Published: 23 September 2019}

\section{References}

Adair JG (1984) The hawthorne effect: a reconsideration of the methodological artifact. J Appl Psychol 69(2):334

Adams SA, Matthews CE, Ebbeling CB, Moore CG, Cunningham JE, Fulton J, Hebert JR (2005) The effect of social desirability and social approval on self-reports of physical activity. Am J Epidemiol 161(4):389-398

Allcott H (2011) Social norms and energy conservation. J Publ Econ 95(9-10):1082-1095

Allcott H, Rogers T (2014) The short-run and long-run effects of behavioral interventions: Experimental evidence from energy conservation. Am Econ Rev 104(10):3003-37

Anderson K, Song K, Lee S, Krupka E, Lee H, Park M (2017) Longitudinal analysis of normative energy use feedback on dormitory occupants. Appl Energy 189:623-639

Bastida L, Cohen JJ, Kollmann A, Moya A, Reichl J (2019) Exploring the role of ict on household behavioural energy efficiency to mitigate global warming. Renew Sust Energ Rev 103:455-462

Breukers S, Mourik R (2013) The end-users as starting point for designing dynamic pricing approaches to change household energy consumption behaviours. Report for Netbeheer Nederland, Project group Smart Grids (Pg SG). Arnhem: March 2013

Chen Y, Martínez J-F, Castillejo P, López L (2018) A privacy-preserving noise addition data aggregation scheme for smart grid. Energies 11(11):2972

Cominola A, Giuliani M, Piga D, Castelletti A, Rizzoli AE (2015) Benefits and challenges of using smart meters for advancing residential water demand modeling and management: A review. Environ Model Softw 72:198-214

Deci EL (1971) Effects of externally mediated rewards on intrinsic motivation.J Personal Soc Psychol 18(1):105

Depuru SSSR, Wang L, Devabhaktuni V (2011) Smart meters for power grid: Challenges, issues, advantages and status. Renew Sust Energ Rev 15(6):2736-2742

Fang X, Misra S, Xue G, Yang D (2012) Smart grid —-the new and improved power grid: A survey. IEEE Commun Surv Tutor 14(4):944-980

Frederiks ER, Stenner K, Hobman EV (2015) Household energy use: Applying behavioural economics to understand consumer decision-making and behaviour. Renew Sust Energ Rev 41:1385-1394

Frederiks ER, Stenner K, Hobman EV, Fischle M (2016) Evaluating energy behavior change programs using randomized controlled trials: Best practice guidelines for policymakers. Energy Res Soc Sci 22:147-164

Frick V, Seidl R, Stauffacher M, Moser C (2017) Promoting energy-saving behaviour: Formal social groups as promising middle actors for municipal interventions. Energy Efficiency 10(6):1539-1551

Froehlich J, Findlater L, Landay J (2010) The design of eco-feedback technology. In: Proceedings of the SIGCHI Conference on Human Factors in Computing Systems, CHI '10. ACM, New York. pp 1999-2008. https://doi.org/10. $1145 / 1753326.1753629$ 
Froehlich J, Findlater L, Ostergren M, Ramanathan S, Peterson J, Wragg I, Larson E, Fu F, Bai M, Patel S, Shwetak L, James A (2012) The design and evaluation of prototype eco-feedback displays for fixture-level water usage data. In: Proceedings of the SIGCHI Conference on Human Factors in Computing Systems, CHI '12. ACM, New York. pp 2367-2376. https://doi.org/10.1145/2207676.2208397

Geelen D, Reinders A, Keyson D (2013) Empowering the end-user in smart grids: Recommendations for the design of products and services. Energy Policy 61:151-161

Gillingham K, Kotchen MJ, Rapson DS, Wagner G (2013) Energy policy: The rebound effect is overplayed. Nature 493(7433):475

Goulden M, Bedwell B, Rennick-Egglestone S, Rodden T, Spence A (2014) Smart grids, smart users?the role of the user in demand side management. Energy Res Soc Sci 2:21-29

Greening LA, Greene DL, Difiglio C (2000) Energy efficiency and consumption—the rebound effect-a survey. Energy Policy 28(6-7):389-401

Hargreaves T, Nye M, Burgess J (2013) Keeping energy visible?exploring how householders interact with feedback from smart energy monitors in the longer term. Energy Policy 52:126-134

Hartman RS (1988) Self-selection bias in the evolution of voluntary energy conservation programs. Rev Econ Stat 70(3):448-458

Karjalainen S (2011) Consumer preferences for feedback on household electricity consumption. Energy Build 43(2-3):458-467

Karlin B (2015) The effects of feedback on energy conservation: A meta-analysis. Psychol Bull 141(6):1205-1227

Kurz T, Gardner B, Verplanken B, Abraham C (2015) Habitual behaviors or patterns of practice?explaining and changing repetitive climate-relevant actions. Wiley Interdiscip Rev Clim Chang 6(1):113-128

Lindenberg S, Steg L (2007) Normative, gain and hedonic goal frames guiding environmental behavior. J Soc Issues 63(1):117-137

Micheel I, Novak J, Fraternali P, Baroffio G, Castelletti AF, Rizzoli A (2015) Visualizing and gamifying water \& energy consumption for behavior change. In: Fostering Smart Energy Applications Workshop (FSEA) 2015 at Interact 2015, Springer. pp 1-4

Munx, The energy efficiency portal. https://munx.ail.ch/it/. Accessed 21 Aug 2019

Nichols AL, Maner JK (2008) The good-subject effect: Investigating participant demand characteristics. J Gen Psychol 135(2):151-166

Ohnmacht T, Schaffner D, Weibel C, Schad H (2017) Rethinking social psychology and intervention design: A model of energy savings and human behavior. Energy Res Soc Sci 26:40-53

Pallot M, Trousse B, Senach B, Scapin D (2010) Living lab research landscape: From user centred design and user experience towards user co-creation, Position Paper

Parag Y, Sovacool BK (2016) Electricity market design for the prosumer era. Nat Energy 1(4):16032

Pichert D, Katsikopoulos KV (2008) Green defaults: Information presentation and pro-environmental behaviour. J Environ Psychol 28(1):63-73

Pitì A, Verticale G, Rottondi C, Capone A, Lo Schiavo L (2017) The role of smart meters in enabling real-time energy services for households: The italian case. Energies 10(2):199

Prochaska JO, Velicer WF (1997) The transtheoretical model of health behavior change. Am J Health Promot 12(1):38-48

Rottondi C, Verticale G, Krauss C (2013) Distributed privacy-preserving aggregation of metering data in smart grids. IEEE J Sel Areas Commun 31(7):1342-1354

Ryan RM, Deci EL (2000) Intrinsic and extrinsic motivations: Classic definitions and new directions. Contemp Educ Psychol 25(1):54-67

Scheider S, Kiefer P, Weiser P, Raubal M, Sailer C (2015) Score design for meaningful gamification. In: Researching gamification: strategies, opportunities, challenges, ethics, Workshop at CHI 2015

Schleich J, Faure C, Klobasa M (2017) Persistence of the effects of providing feedback alongside smart metering devices on household electricity demand. Energy Policy 107:225-233

Tiefenbeck V (2016) On the magnitude and persistence of the hawthorne effect- evidence from four field studies. In: Proc. European Conference on Behaviour and Energy Efficiency. pp 1-6

Tiefenbeck V, Wörner A, Schöb S, Fleisch E, Staake T (2019) Real-time feedback promotes energy conservation in the absence of volunteer selection bias and monetary incentives. Nat Energy 4(1):35

Truelove HB, Carrico AR, Weber EU, Raimi KT, Vandenbergh MP (2014) Positive and negative spillover of pro-environmental behavior: An integrative review and theoretical framework. Glob Environ Chang 29:127-138

Venkatesh V, Thong JY, Xu X (2012) Consumer acceptance and use of information technology: extending the unified theory of acceptance and use of technology. MIS Quarterly 36(1):157-178

Verbong GP, Beemsterboer S, Sengers F (2013) Smart grids or smart users?involving users in developing a low carbon electricity economy. Energy Policy 52:117-125

Vine E, Sullivan M, Lutzenhiser L, Blumstein C, Miller B (2014) Experimentation and the evaluation of energy efficiency programs. Energy Efficiency 7(4):627-640

Weiser P, Bucher D, Cellina F, De Luca V (2015) A taxonomy of motivational affordances for meaningful gamified and persuasive technologies. In: Envirolnfo and ICT for Sustainability 2015. Atlantis Press. https://doi.org/10.2991/ict4senv-15.2015.31

Wemyss D, Castri R, Cellina F, De Luca V, Lobsiger-Kägi E, Carabias V (2018) Examining community-level collaborative vs. competitive approaches to enhance household electricity-saving behavior. Energy Efficiency 11(8):2057-2075

Wemyss D, Cellina F, Lobsiger-Kägi E, de Luca V, Castri R (2019) Does it last?long-term impacts of an app-based behavior change intervention on household electricity savings in switzerland. Energy Res Soc Sci 47:16-27

Yan Y, Qian Y, Sharif H, Tipper D (2012) A survey on cyber security for smart grid communications. IEEE Commun Surv tutor 14(4):998-1010

Yan Y, Qian Y, Sharif H, Tipper D (2013) A survey on smart grid communication infrastructures: Motivations, requirements and challenges. IEEE Commun Surv Tutor 15(1):5-20 
Zheng M, Meinrenken CJ, Lackner KS (2014) Agent-based model for electricity consumption and storage to evaluate economic viability of tariff arbitrage for residential sector demand response. Appl Energy 126:297-306

Zoha A, Gluhak A, Imran MA, Rajasegarar S (2012) Non-intrusive load monitoring approaches for disaggregated energy sensing: A survey. Sensors 12(12):16838-16866

\section{Publisher's Note}

Springer Nature remains neutral with regard to jurisdictional claims in published maps and institutional affiliations.

Submit your manuscript to a SpringerOpen ${ }^{\mathcal{O}}$ journal and benefit from:

- Convenient online submission

- Rigorous peer review

- Immediate publication on acceptance

- Open access: articles freely available online

- High visibility within the field

- Retaining the copyright to your article

Submit your next manuscript at $\boldsymbol{\nabla}$ springeropen.com 